\title{
Titania Nanofibers: A Potential Adsorbent for Mercury and Lead Uptake
}

\author{
Abhilasha Dixit, P. K. Mishra, and M. S. Alam
}

\begin{abstract}
The present investigation focuses on testing the adsorptive behaviour of laboratory synthesized titania nanofibers towards $\mathrm{Hg}(\mathrm{II})$ and $\mathrm{Pb}(\mathrm{II})$ in the aqueous system. The BET analysis confirmed that the electrospinned nanofibers were confirmed to possess a large surface area of $740 \mathrm{~m}^{2} / \mathrm{g}$. The fiber mats were analysed by EDX, which confirmed the adsorption of the metals on the fiber surface. SEM revealed the smooth morphology and continuous nature of the fibers. The effect of $\mathrm{pH}$, contact time and adsorbent dose is compared for both the metals. At the most optimized conditions, highest uptake of $95.5 \%$ was observed for $0.01 \mathrm{mg} / \mathrm{L} \quad \mathrm{Hg}(\mathrm{II})$ concentration while it was $83.8 \%$ for $0.5 \mathrm{mg} / \mathrm{L} \mathrm{Pb}(\mathrm{II})$ concentration. Since the rate limiting steps in adsorption are of vital importance in order to define the rate parameters for design purposes, the present study takes into account Weber and Morris and Boyd mass transfer diffusion models for both $\mathrm{Hg}$ (II) and $\mathrm{Pb}(\mathrm{II})$ adsorption on titania nanofibers. The equilibrium data were then analyzed using Langmuir and Freundlich sorption models and the characteristic sorption parameters for each isotherm were determined. The discussion also focuses on few of the recently used adsorbents for heavy metal uptake and their comparison with the present study.
\end{abstract}

Index Terms-Adsorption, heavy metals, isotherm, mass transfer, nano adsorbent.

\section{INTRODUCTION}

Water pollution affects the entire biosphere and so is a problem of great concern. The increasing industrialization has played a very important in the degradation of natural water resources. The direct or indirect discharge from the industries into the water bodies demote the water quality and make it unsuitable for aquatic as well human life. Metals reach the environment naturally through the weathering of soils and rocks, and through anthropogenic activities like mining, processing, etc. The presence of heavy metals in effluent streams range from troublesome to being severely life threatening. Heavy metal contaminated aqueous streams have become a global concern due to their carcinogenicity and delirious effects on human health.

Mercury and Lead appear in the list of chemicals of major public concern declared by WHO [1]. While mercury with a maximum allowable USEPA discharge limit of $0.001 \mathrm{mg} / \mathrm{L}$ is considered to be a global pollutant, lead has a maximum discharge limit of $0.015 \mathrm{mg} / \mathrm{L}$ [2]. Their presence in

Manuscript received June 10, 2016; revised September 25, 2016

Abhilasha Dixit and M. S. Alam are with the Department of Chemical Engineering, Motilal Nehru National Institute of Technology, Allahabad (UP) 221004, India (e-mail: adixit.chem@ gmail.com, msalam@mnnit.ac.in).

P. K. Mishra is with the Department of Chemical Engineering, Indian Institute of Technology, IIT (BHU), Varanasi (UP) 221005, India (e-mail: pkmishra.che@itbhu.ac.in). environment is of significant concern because of their extreme toxicity, persistence and bioaccumulation properties [3]. Once in the environment, mercury gets converted into methyl-mercury chloride, which is its most toxic form. The major industries releasing mercury-laden wastewaters into environment are fertilizers, mining, mineral processing and tanning, etc. The major sources of lead in the environment are through metal plating and paint industries [2]. Human exposure to mercury severely produces neurological imbalance, anxiety, restlessness and lung disease, etc. while lead affects kidneys and nervous system.

Conventional techniques like chemical precipitation and ion exchange for heavy metal remediation have their own respective disadvantage of sludge production and being economically infeasible. The stringent laws and tight regulation on heavy metal bearing wastewaters being discharged into the water stream lead to emergence of technically advanced and super effective treatment methods. Adsorption with its advantage of operation and design flexibility has come up as a very promising technique for heavy metal uptake. Numerous studies have highlighted the efficient use of modified activated carbons [4], chitosan [5], carbon nanotubes [6], etc for heavy metal adsorption. The advantage of using nano adsorbents for heavy metal remediation from wastewaters lies in their properties such as high porosity and enhanced structural properties suitable for adsorption process. Nanostructured metal oxide materials have attracted considerable attention because of their potential applications in many areas such as electronics, photonics, sensors and catalysis [7]-[9]. Nanofibers are an excellent new class of materials being used for numerous applications such as insulation, medical, cosmetics and filtration, etc. Various approaches for preparation of nano and microstructures of titania have been reported, such as sol-gel processes, pyrolysis, electrospinning, chemical vapor deposition and hydrothermal methods [10]-[12]. Electrospinning has recently attracted much attention for nano-fiber synthesis since it offers flexibility of control over morphology, porosity, functionality and composition.

Most of the studies have worked on higher metal concentration [13]-[15] and the difficulty in removing the metals at lower concentrations is still a challenge. The present study takes up the adsorption of $\mathrm{Hg}$ (II) and $\mathrm{Pb}$ (II) onto laboratory synthesized titania nanofibers from aqueous solutions at a lower concentration actually found in industrial efluents. A comparison of the effect of $\mathrm{pH}$, contact time and adsorbent dose on adsorption of $\mathrm{Hg}$ (II) and $\mathrm{Pb}$ (II) is presented. Mass transfer mechanism is discussed in details via Weber and Morris and Boyd models. The adsorption data is dynamically studied through Langmuir and Freundlich isotherm models. 


\section{MATERIAL AND METHODS}

\section{A. Titania Nanofiber Synthesis}

The Titania nanofibers (TNF) were synthesized using a combination of sol gel and electrospinning techniques. Solution prepared with Titanium Tetraisopropoxide (TTIP), ethanol and acetone in a fixed ratio was mixed with a solution of Polyvinylpyrrolidone (PVP) and ethanol. This mixture was injected to a syringe and the fibers were collected at the collecting plate. After hydrolysis at room temperature, the fibers were calcined in muffle furnace. The fiber synthesis process is described in details in our previous work [16]. Fig. 1 schematically presents the spinning process. A constant solution-feeding rate of $1 \mathrm{~mL} / \mathrm{h}$ regulated by the syringe pump and a positive high voltage of $12 \mathrm{kV}$ ensured the steady deposition of nanofibers on the collector plate. As the accelerated jet moved towards the collector, the solvent gets evaporated, leaving only ultra thin fibers on the collector plate. The process continued until all the solution in the syringe was used up.

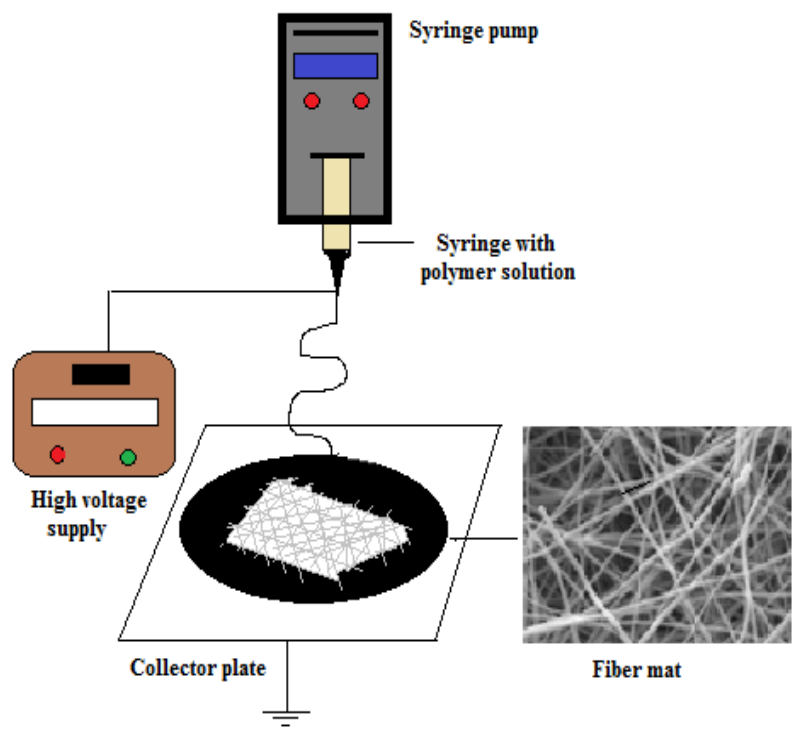

Fig. 1. Schematic representation of electrospinning process.

\section{B. Adsorption Experiments}

Analytical grade $\mathrm{HgCl}_{2}$ and $\mathrm{PbNO}_{3}$ were used to prepare $\mathrm{Hg}^{2+}$ and $\mathrm{Pb}^{2+}$ stock solution, respectively. The metal adsorption studies were carried out in batch mode at varying parameters with $0.01 \mathrm{mg} / \mathrm{L} \mathrm{Hg}^{2+}$ and $0.5 \mathrm{mg} / \mathrm{L} \mathrm{Pb}^{2+}$, one metal at a time. Measured quantities of TNF were dosed in metal containing aqueous solutions, and $\mathrm{pH}$ of the solution was varied between 4.0-8.0, contact time from 0 to $240 \mathrm{~min}$ and adsorbent dose from 0.01 to $0.07 \mathrm{~g} / \mathrm{L}$. The aliquots at the outlet were tested for remaining $\mathrm{Hg}^{2+}$ or $\mathrm{Pb}^{2+}$ at different time intervals using ICP technique. The amount of metal ion at equilibrium, $\mathrm{q}_{\mathrm{e}}$ and percentage metal removal is calculated from the mass balance Eq. (1) and (2) respectively. V is the volume of the solution; $\mathrm{W}$ is the weight of the adsorbent; $\mathrm{C}_{0}$ and $\mathrm{C}_{\mathrm{e}}$ are the initial and equilibrium metal concentrations respectively [17].

$$
\begin{aligned}
q_{e} & =\frac{\left(C_{0}-C_{e}\right)}{W} \times V \\
\% R & =\frac{\left(C_{0}-C_{e}\right)}{C_{0}} \times 100
\end{aligned}
$$

\section{RESUlTS AND DISCUSSION}

\section{A. Titania Nanofiber Synthesis}

The fiber synthesis carried out with varying process parameters revealed morphological changes. Fig. 2 represents the effect of process parameters on average diameter of fiber and the effect on fiber morphology is discussed in details in our previous work [16]. The increase in PVP concentration from $6 \mathrm{wt} \%$ to $12 \mathrm{wt} \%$ increases the average diameter from $147 \mathrm{~nm}$ to $297 \mathrm{~nm}$ (Fig. 2a). This increase in the diameter is attributed to the increase in viscosity of the spinning solution. However, futher increase in the PVP concentration led to the non-uniform ejection of the jet. Similarly, the increase in solution viscosity with the increase in precursor concentration from $1.5 \mathrm{~mL}$ to $3.0 \mathrm{~mL}$ seems to increase the average diameter from $297 \mathrm{~nm}$ to 443 nm (Fig. 2b). From Fig. 2c it can be seen that the average diameter of the fiber decreases from $422 \mathrm{~nm}$ to $155 \mathrm{~nm}$ as the calcination temperature is increased from 500 to $800^{\circ} \mathrm{C}$. This reduction in fiber diameter can be ascribed to the shrinkage of fiber along the radial direction at high temperatures. At the most optimized conditions, perfectly smooth and well-aligned fibers with BET surface area of $740 \mathrm{~m}^{2} / \mathrm{g}$ were observed. A surface area as large as this was sufficient enough for heavy metal adsorption application.

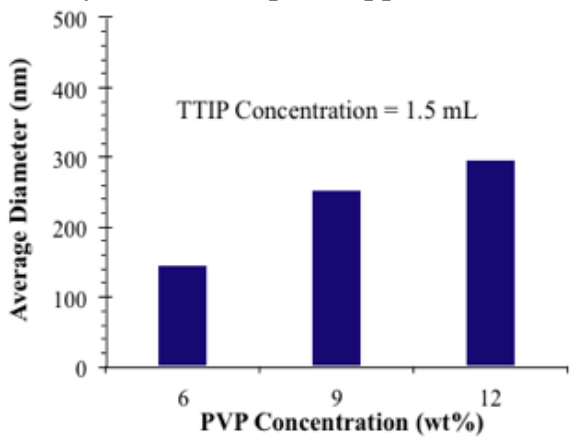

(a)

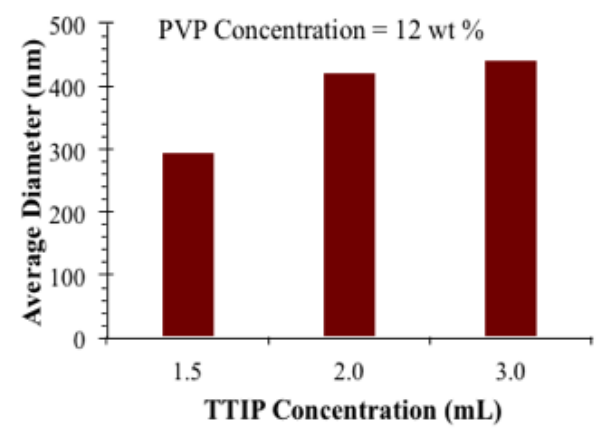

(b)

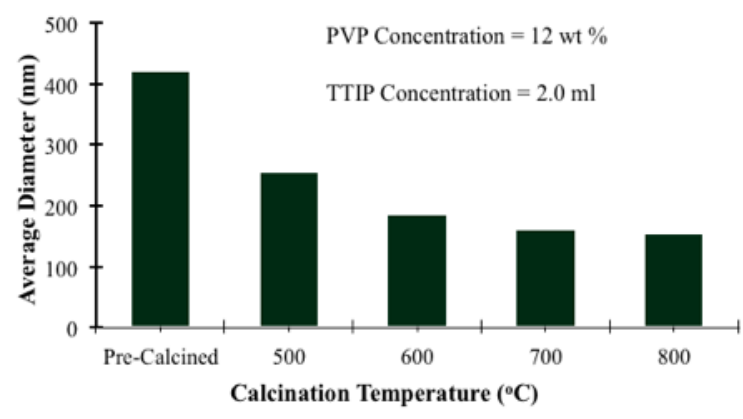

(c)

Fig. 2. Effect of process parameters on average diameter of fiber. 


\section{B. Metal Adsorption on TNF Effect of $p H$}

The effect of $\mathrm{pH}$ on $\mathrm{Hg}(\mathrm{II})$ and $\mathrm{Pb}(\mathrm{II})$ adsorption by $\mathrm{TNF}$ was studied in the $\mathrm{pH}$ value range of 4.0 to 8.0. The results are presented in Fig. 3. It is clearly depicted from the figure that the metal adsorption onto TNF initially increases with increasing $\mathrm{pH}$ value of the solution up to a value of 6.0 and 5.0 for $\mathrm{Hg}(\mathrm{II})$ and $\mathrm{Pb}(\mathrm{II})$, respectively. Thereafter it decreases with further increase in the $\mathrm{pH}$ value. This phenomena can be explained as the adsorption of metal ions (M) through exchange reactions stated in Eq. (3)-(5):

$$
\begin{aligned}
& \mathrm{Ti}-\mathrm{OH}+\mathrm{M}^{2+} \rightarrow \mathrm{TiO}-\mathrm{M}^{+}+\mathrm{H}^{+} \\
& \mathrm{Ti}-\mathrm{OH}(\mathrm{OH})_{2}+\mathrm{M}^{2+} \rightarrow \mathrm{Ti}(\mathrm{OH})_{2} \mathrm{O}-\mathrm{M}^{+}+\mathrm{H}^{+} \\
& \mathrm{TiOH}^{3+}+\mathrm{M}^{2+} \rightarrow \mathrm{TiO}-\mathrm{M}^{4+}+\mathrm{H}^{+}
\end{aligned}
$$

The above reactions clearly indicate that metal ion adsorption increases with decreasing proton concentration or increasing $\mathrm{pH}$ value. In addition, the effect of $\mathrm{pH}$ can be explained by considering the surface charge on the adsorbent. The low adsorption at smaller $\mathrm{pH}$ values is due to the competition of protons with metal cations for the same adsorption sites [18]. As the $\mathrm{pH}$ increases, this competition decreases which enhances the metal uptake capacity of the adsorbent. At above a certain $\mathrm{pH}$ (6 for $\mathrm{Hg}$ (II) and 5 for $\mathrm{Pb}(\mathrm{II}))$, the metal uptake again starts decreasing. This is due to the fact that above the $\mathrm{pH}$ point of precipitation $\left(\mathrm{pH}_{\mathrm{ppt}}\right)$ for each metal, metal hydroxide precipitation occurs, thereby reducing the adsorption of metal ions onto the adsorbent surface.

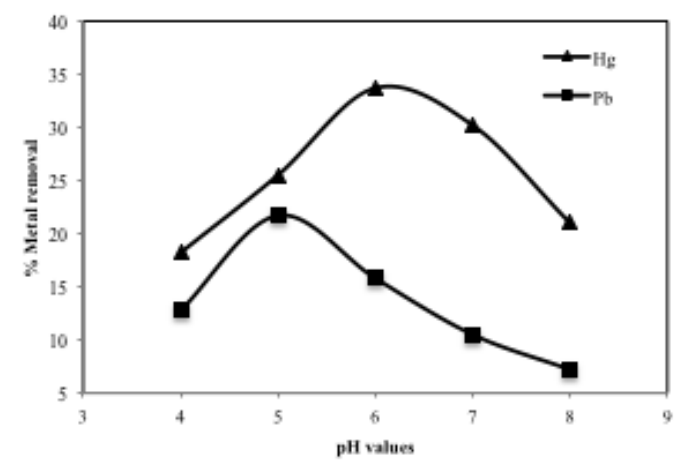

Fig. 3. Effect of $\mathrm{pH}$ on $\mathrm{Hg}$ (II) and $\mathrm{Pb}$ (II) adsorption onto TNF.

\section{1) Energy dispersive $X$-ray analysis}

The elemental composition and morphology of the TNF mat after metal adsorption was analysed by SEM-EDX spectroscopy. From Fig. 4, it can be seen that the fibers maintained their morphology and did not get affected by the adsorption experiments for both $\mathrm{Hg}$ (II) and $\mathrm{Pb}$ (II). Fig. 4a and Fig. 4b, represents the post adsorption result of $\mathrm{Hg}$ (II) and $\mathrm{Pb}(\mathrm{II})$ ion, respectively. A significant metal ion peak is observed in both the cases which confirms the adsorption of both $\mathrm{Hg}(\mathrm{II})$ and $\mathrm{Pb}(\mathrm{II})$ metal ions in their respective sets of adsorption experiments. The presence of Ti peak points to the fact that not all the titania has been used up and it can still be reused.

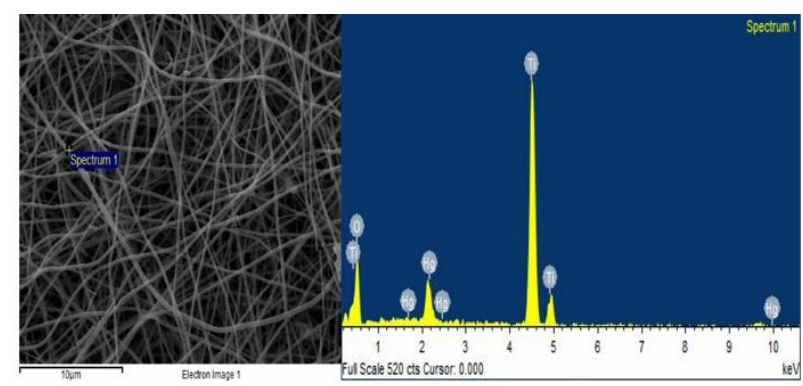

(a)

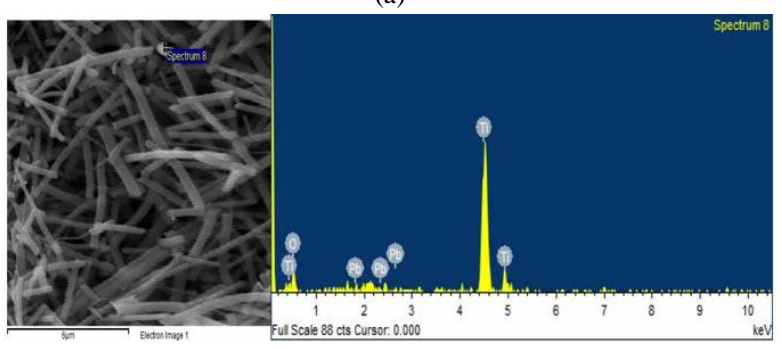

(b)

Fig. 4. TNF SEM and EDX after metal adsorption (a) $\mathrm{Hg}$ (II) (b) $\mathrm{Pb}$ (II)

\section{2) Effect of contact time}

The change in metal concentration is plotted in Fig. 5 as a function of time in the range 0 to $240 \mathrm{~min}$. The equilibrium was reached at $210 \mathrm{~min}$ with a maximum of $63.5 \% \mathrm{Hg}$ (II) uptake. In case of $\mathrm{Pb}(\mathrm{II})$, TNF took $180 \mathrm{~min}$ for maximum uptake of $50.9 \%$. In both experiments, the metal adsorption increases rapidly initially, until a point after which no significant uptake is observed. High initial rate of adsorption must be due to the availability of greater number of sites for metal ion adsorption. With increase in contact time, as the equilibrium approaches and the number of vacant surface sites decrease and the adsorption rate slows down after a certain period of time due to the formation of repulsive forces between the metals on the solid surface and in the liquid phase.

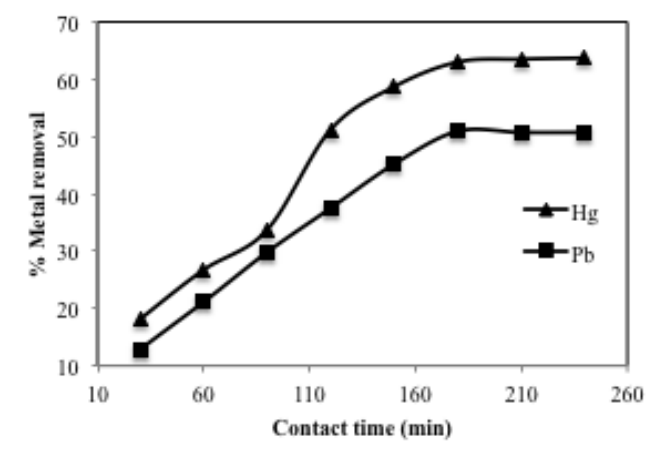

Fig. 5. Effect of contact time on metal adsorption onto TNF.

\section{3) Effect of adsorbent dose}

The effect of TNF dose on metal adsorption was investigated in the range 0.01 to $0.07 \mathrm{~g} / \mathrm{L}$ for both $\mathrm{Hg}(\mathrm{II})$ and $\mathrm{Pb}$ (II) (Fig. 6). TNF dose of $0.05 \mathrm{~g} / \mathrm{L}$ gave a maximum of $95.5 \% \mathrm{Hg}(\mathrm{II})$ and $83.8 \% \mathrm{~Pb}(\mathrm{II})$ ion removal, respectively. It is observed that the percentage removal of both the metal increases with the increase in adsorbent dosage and at a particular dose, the removal reaches almost a constant value. The initial increase in the efficiency of adsorbents can be 
attributed to the fact that with an increase in adsorbent dose at a fixed metal concentration provides more adsorbent surface area and hence more adsorption sites are available for the metal ions adsorption. The adsorption reaches a stable value, i.e., equilibrium after which further increase in adsorbent dose doesn't significantly contribute to the process.

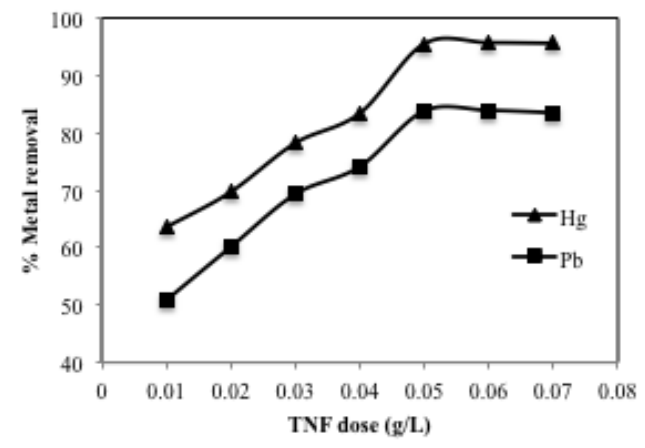

Fig. 6. Effect of TNF dose on metal adsorption onto TNF.

\section{Mass Transfer Mechanism}

The rate-limiting step (slowest step of the reaction) is an important factor to be determined so as to establish the mechanism involved for transportation of mass. The intra-particle and fluid-film diffusion mass transfer limitations are verified for both $\mathrm{Hg}$ (II) and $\mathrm{Pb}$ (II) using Weber \& Morris and Boyd models (Fig. 7(a)-(c)). The plot of $q_{t}$ versus $t^{0.5}$ (Eq. (6)) represents intra-particle diffusion, where $q_{t}$ represents adsorption capacity at any time $\mathrm{t}$ and $k_{i}$ is intra-particle diffusion rate constant $\left(\mathrm{mg} / \mathrm{g} \mathrm{min}^{1 / 2}\right)$ [19]. Eq. (7) represents the Boyd kinetic model where $\mathrm{F}\left(q_{t} / q_{e}\right)$ is the fractional attainment of equilibrium at time $t, \mathrm{~B}$ is the Boyd constant, $q_{t}$ and $q_{e}$ are the amounts of metal ion adsorbed at time and at equilibrium, respectively [20].

$$
\begin{gathered}
q_{t}=k_{i} \sqrt{t} \\
F=1-\frac{6}{\pi^{2}} \sum_{n=1}^{\infty} \frac{1}{n^{2}} e^{-n^{2} B t}
\end{gathered}
$$

The value of intra-particle constant $\left(k_{i}\right)$ obtained was 0.0052 and $0.21 \mathrm{mmol} / \mathrm{g} \mathrm{min}^{1 / 2}$ for $\mathrm{Hg}$ (II) and $\mathrm{Pb}(\mathrm{II})$, respectively (Fig. 7(a)-(b)). For $\mathrm{Hg}$ (II) adsorption mass transfer mechanism, the Weber \& Morris model provided a higher $R^{2}$ value of 0.939 than the Boyd model $R^{2}$ value of 0.847. Similarly for $\mathrm{Pb}(\mathrm{II})$ mass transfer mechanism, again Weber \& Morris model provided a higher value $R^{2}$ value of 0.9628 than the Boyd model $R^{2}$ value of 0.939 . For intra-particle diffusion model, the deviation of the data from linearity would indicate that the rate-limiting step should be the boundary layer (film) diffusion. The plots (Fig. 7(a) \& (b)) feature three stages; initial curved portion due to external mass transfer, followed by an intermediate linear portion due to intra-particle diffusion, and a plateau up to the equilibrium stage where intra-particle diffusion starts to slow down due to extremely low solute concentrations in the solution. For Boyd model too, the linear plots of $[-\ln (1-F)]$ versus $t$ (Fig. 7(c) with zero intercept would suggest that the kinetics of the adsorption process is controlled by diffusion through the liquid film surrounding the solid adsorbent. It is also observed that the Boyd plots did not pass through the origin and had lower regression values for $\mathrm{Hg}$ (II) and $\mathrm{Pb}(\mathrm{II})$, respectively. Hence, this system seems to follow a complex process with none of the single mechanism taking the complete charge.

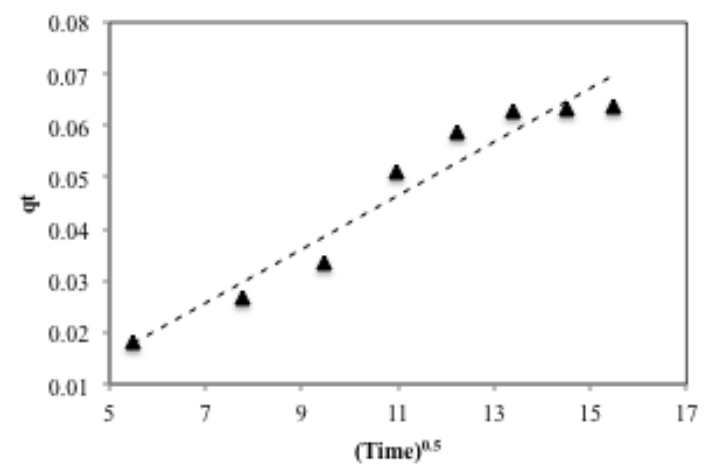

(a)

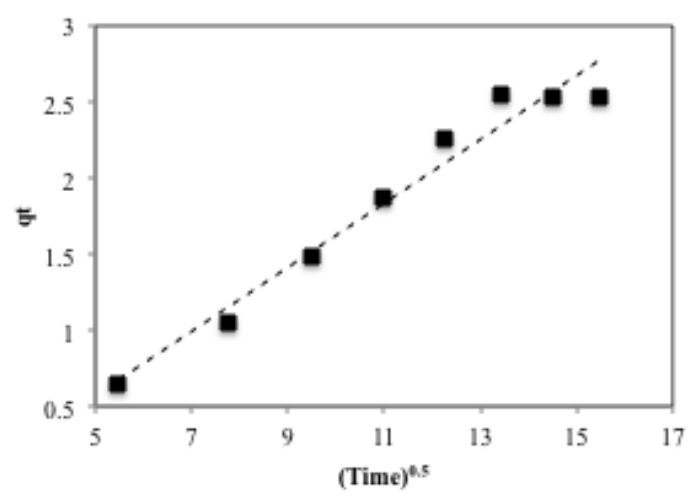

(b)

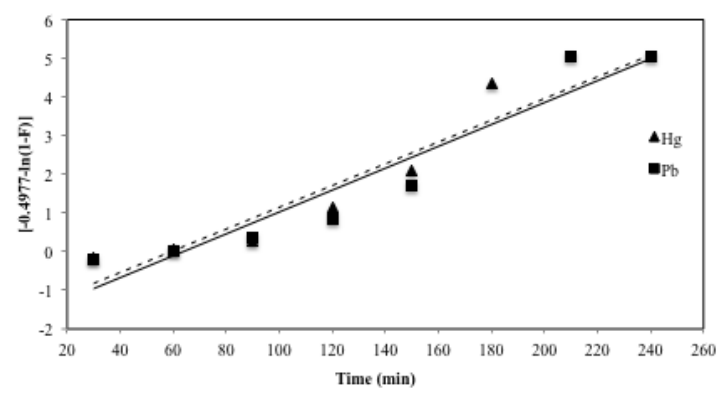

(c)

Fig. 7. Mass transfer mechanism model (a) Weber and Morris for $\mathrm{Hg}$ adsorption (b) Weber and Morris for $\mathrm{Pb}$ adsorption (c) Boyd for $\mathrm{Hg}$ and $\mathrm{Pb}$ adsorption.

\section{Adsorption Kinetics}

Adsorption isotherms are empirical models representing the amount of material bound at the surface as a function of material present in bulk at constant temperature. Langmuir isotherm represents monolayer adsorption and the equation follows Henry's law while Freundlich model assumes multilayer adsorption. Eq. (8) and (9) represent Langmuir and Freundlich models respectively where, $Q_{m}$ represents the maximum amount of metal ion adsorbed, $C_{e}$ is the metal concentration at equilibrium, $k_{L}$ is Langmuir constant and $k_{f}$ Freundlich constant [21], [22].

$$
\frac{C_{e}}{Q_{e}}=\frac{1}{Q_{m} k_{L}}+\frac{C_{e}}{Q_{m}}
$$




$$
\log Q_{e}=\log k_{f}+\frac{1}{n} \log C_{e}
$$

The equilibrium adsorption data for $\mathrm{Hg}(\mathrm{II})$ and $\mathrm{Pb}(\mathrm{II})$ were plotted using Langmuir and Freundlich isotherms and the data are enlisted in Table I. It can be seen that, for both $\mathrm{Hg}(\mathrm{II})$ and $\mathrm{Pb}(\mathrm{II})$, the $R^{2}$ values in case of Langmuir and Freundlich isotherms were satisfactory. Further, the factors, $R_{L}$ for Langmuir and $(1 / n)$ for Freundlich isotherm should ideally be below 1 , to indicate the favorability of the process. The factor $\mathrm{R}_{\mathrm{L}}$ and $1 / \mathrm{n}$ represents the favorability of the process through Langmuir and Freundlich, respectively. When it is greater than 1 , the reaction is unfavorable; when between $0-1$, it represents favorable conditions and when it is equal to 1 , it represents linear relationship. From the table, it can be observed that the value of $R_{L}$ for $\mathrm{Hg}$ (II) is very close to 1 while that of $1 / n$ is well below 1 . On the contrary, for $\mathrm{Pb}$ (II) the $1 / n$ factor is much higher than 1 , which completely rejects its applicability. Hence, the equilibrium isotherm behavior for $\mathrm{Hg}(\mathrm{II})$ and $\mathrm{Pb}(\mathrm{II})$ adsorption follows Freundlich and Langmuir isotherm patterns, respectively.

\begin{tabular}{|c|c|c|c|}
\hline Metal ion & Isotherm & Constants & Values \\
\hline \multirow{7}{*}{$\mathrm{Hg}$ (II) } & \multirow{4}{*}{ Langmuir } & $q_{m}$ & 6.544 \\
\hline & & $b$ & 0.038 \\
\hline & & $R_{L}$ & 0.9 \\
\hline & & $R^{2}$ & 0.96 \\
\hline & \multirow{3}{*}{ Freundlich } & $k_{f}$ & 3.237 \\
\hline & & $1 / n$ & 0.687 \\
\hline & & $R^{2}$ & 0.948 \\
\hline \multirow{7}{*}{$\mathrm{Pb}(\mathrm{II})$} & \multirow{4}{*}{ Langmuir } & $q_{m}$ & 2.563 \\
\hline & & $b$ & 0.570 \\
\hline & & $R_{L}$ & 0.867 \\
\hline & & $R^{2}$ & 0.867 \\
\hline & \multirow{3}{*}{ Freundlich } & $k_{f}$ & 0.865 \\
\hline & & $1 / n$ & 2.13 \\
\hline & & $R^{2}$ & 0.936 \\
\hline
\end{tabular}

\section{COMPARISON WITH RECENT WORKS}

Numerous earlier works have used nano-sized adsorbents for removing $\mathrm{Hg}^{2+}$ from aqueous solutions in batch experiments. Table II represents some of the recent works on mercury adsorption in batch mode using nano adsorbents. Manganese chloride nanoparticles [23], functionalized iron nanoparticles [13], [24], [25] with particle diameters 100, 40-50 and $10 \mathrm{~nm}$ respectively could remove more than $95 \%$ $\mathrm{Hg}$ (II) at various concentrations. Titania nano particles [14], [26] with diameter ranging from 3-10 $\mathrm{nm}$ and large surface area had adsorption capacity of more than $120 \mathrm{mg} / \mathrm{g} \mathrm{Hg}$ (II) at concentrations ranging from $100-800 \mathrm{mg} / \mathrm{L}$ with or without UV illumination. More than $90 \%$ of $40-100$ ppm $\mathrm{Hg}(\mathrm{II})$ in aqueous media was removed by thiol functionalized magnetite nanoparticles [15]. Iron oxide nano composite [27] and nano polymer [28] showed a good affinity over a range of metal ion concentration, with adsorption efficiency around 167.8 and 256.4, respectively. $\mathrm{Fe}_{2} \mathrm{O}_{3}-\mathrm{Al}_{2} \mathrm{O}_{3}$ nano fibers [29] had a small surface area of $9.6 \mathrm{~m}^{2} / \mathrm{g}$ but exhibited $\mathrm{Hg}$ (II) adsorption of $89 \%$. Most of the mechanisms followed
Langmuir isotherm. However few works fitted well to Freundlich isotherm as well. The works mentioned above have targeted higher metal concentrations while the need of the hour is to target the concentrations close to the ones found in real industrial effluents. The lab synthesized TNF used in the present work had very high affinity for $\mathrm{Hg}^{2+}$ as well as $\mathrm{Pb}^{2+}$ metal ions. The main reason behind this seems to be the high surface area. Adsorption, being a surface phenomenon largely depends on surface area and with such high surface areas comes higher removal efficiencies.

TABLE II: COMPARISON WITH RECENT WORKS

\begin{tabular}{|c|c|c|c|c|}
\hline Nano adsorbents & Properties & $\begin{array}{l}\text { Working } \\
\text { conditions }\end{array}$ & Findings & Ref \\
\hline $\begin{array}{l}\mathrm{Mn}(\mathrm{III}) \mathrm{Cl} \mathrm{NP} \text { on } \\
\mathrm{SiO}_{2} / \mathrm{Al}_{2} \mathrm{O}_{3} \\
\text { mixed oxide } \\
\text { support }\end{array}$ & $\begin{array}{l}\mathrm{D}=5-30 \\
\mathrm{SA}=243\end{array}$ & $\begin{array}{l}\mathrm{C}=0.5-400, \\
\mathrm{~A}=0-41.5, \\
\mathrm{pH}=1-12, \mathrm{t} \\
=0-12, \mathrm{~T} \\
=25-80\end{array}$ & $\begin{array}{l}\mathrm{Q}=289.5, \\
\text { I-Langmuir } \\
\text { Freundlich } \\
\text { O-Second }\end{array}$ & 23 \\
\hline $\begin{array}{c}\mathrm{Fe}_{3} \mathrm{O}_{4} \\
\text { Hydroxyapatite } \\
\text { NP }\end{array}$ & $\mathrm{D}=100$ & $\begin{array}{l}\mathrm{C}=2.5 \mathrm{e}^{-8} \\
\mathrm{~A}=0.1-4, \\
\mathrm{pH}=3-9, \mathrm{t} \\
=0-1, \mathrm{~T}= \\
10-40, \mathrm{~S}= \\
200\end{array}$ & $\begin{array}{c}\mathrm{R}=98, \\
\text { I-Langmuir } \\
\text { O-Second }\end{array}$ & 24 \\
\hline $\begin{array}{c}\mathrm{Fe}_{3} \mathrm{O}_{4} \mathrm{NPs} \\
\text { modified with } \\
\text { 2-mercapto-benzo } \\
\text { thiazole }\end{array}$ & $\mathrm{D}=40-50$ & $\begin{array}{c}\mathrm{C}=20-100 \\
\mathrm{ng} / \mathrm{L}, \mathrm{A}= \\
0.06-2.4, \\
\mathrm{pH}=1-11, \mathrm{t} \\
\quad=0-0.5\end{array}$ & $\begin{array}{c}\mathrm{R}=98.6 \\
\text { I-Langmuir }\end{array}$ & 13 \\
\hline $\begin{array}{c}\text { Polyrhodanine } \\
\text { coated } \gamma-\mathrm{Fe}_{2} \mathrm{O}_{3} \\
\text { NPs }\end{array}$ & $\begin{array}{c}D=10 \\
S A=94.65\end{array}$ & $\begin{array}{c}\mathrm{C}=1-80, \mathrm{~A} \\
=0.5, \mathrm{pH}= \\
2-8, \mathrm{t}= \\
0-12, \mathrm{~T}= \\
25\end{array}$ & $\begin{array}{c}\mathrm{R}=94.5 \\
\text { I-Freundlich } \\
\text { O-Second }\end{array}$ & 25 \\
\hline $\mathrm{TiO}_{2} \mathrm{NP}$ & $\begin{array}{c}D=10.19 \\
S A=98.74\end{array}$ & $\begin{array}{c}\mathrm{C}= \\
100-800, \mathrm{~A} \\
=1-5, \mathrm{pH}= \\
2-9, \mathrm{t}= \\
0.5-9, \mathrm{~T}= \\
30-60\end{array}$ & $\begin{array}{c}Q=166.66 \\
\text { I-Freundlich } \\
\text {, O-Second }\end{array}$ & 14 \\
\hline $\mathrm{TiO}_{2} \mathrm{NPs}(+\mathrm{UV})$ & $\begin{array}{r}\mathrm{D}=9.1 \\
\mathrm{SA}>200\end{array}$ & \multirow{2}{*}{$\begin{array}{l}\mathrm{C}=100, \mathrm{~A} \\
=10, \mathrm{pH}= \\
6, \mathrm{t}=1.5, \mathrm{~T} \\
=25-45\end{array}$} & $\begin{array}{c}Q=101 \\
E_{a}=25 \\
\text { I-Langmuir } \\
\text { O-First }\end{array}$ & \multirow{2}{*}{26} \\
\hline $\begin{array}{c}\mathrm{TiO}_{2} / \text { montmorillo } \\
\text { nite (+ UV) }\end{array}$ & $\begin{array}{r}\mathrm{D}=3.1 \\
\mathrm{SA}=239\end{array}$ & & $\begin{array}{c}\mathrm{Q}=123.8 \\
\mathrm{Ea}=22.6 \\
\text { I-Langmuir } \\
\text { O-First }\end{array}$ & \\
\hline $\begin{array}{l}\text { Thiol-functionaliz } \\
\text { ed silica-coated } \\
\text { magnetite NPs }\end{array}$ & $\mathrm{D}=50$ & $\begin{array}{l}\mathrm{C}=40-100 \\
\mu \mathrm{g} / \mathrm{L}, \mathrm{A}= \\
4-8 \mathrm{mg} / \mathrm{L}, \\
\mathrm{pH}=2-9, \mathrm{t} \\
=0.25, \mathrm{~T}= \\
10-35\end{array}$ & $\begin{array}{c}\mathrm{R}=93.76 \\
\text { I-Freundlich }\end{array}$ & 15 \\
\hline $\begin{array}{l}\text { Amino } \\
\text { functionalized } \\
\mathrm{Fe}_{3} \mathrm{O}_{4} \text { graphene } \\
\mathrm{NC}\end{array}$ & $\begin{aligned} \mathrm{D} & =38.57 \\
\mathrm{SA} & =62.43\end{aligned}$ & $\begin{array}{l}\mathrm{C}=3, \mathrm{~A}= \\
0.16, \mathrm{pH}= \\
1-9, \mathrm{t}=0-5 \\
\mathrm{~T}=20-40\end{array}$ & $\begin{array}{c}\mathrm{Q}=167.8 \\
\mathrm{I}-\mathrm{Langmuir} \\
\mathrm{O}-\text { Second }\end{array}$ & 27 \\
\hline $\begin{array}{l}\text { Mercapto } \\
\text { functionalized } \\
\text { nano-magnetic } \\
\mathrm{Fe}_{3} \mathrm{O}_{4} \text { polymers }\end{array}$ & $\mathrm{D}=40$ & $\begin{array}{l}C=20-100, \\
A=0-1, p H \\
=2-6, t= \\
0-3, T= \\
25-45\end{array}$ & $\begin{array}{c}\mathrm{Q}=256.4, \\
\text { I-Freundlich } \\
\text { O-Second }\end{array}$ & 28 \\
\hline $\mathrm{Fe}_{2} \mathrm{O}_{3}-\mathrm{Al}_{2} \mathrm{O}_{3} \mathrm{NF}$ & $\begin{array}{c}D= \\
200-500 \\
S A=9.6\end{array}$ & $\begin{array}{l}\mathrm{C}=5-50, \mathrm{~A} \\
=2.5, \mathrm{pH}= \\
2-8, \mathrm{t}=0-3, \\
\mathrm{~T}=\mathrm{RT}\end{array}$ & $\begin{array}{c}\mathrm{R}=89, \\
\text { I-Langmuir } \\
\text { O-Second }\end{array}$ & 29 \\
\hline
\end{tabular}




\section{CONCLUSION}

The present study took up the synthesis and application of titania nanofibers with emphasis on its adsorption behavior for $\mathrm{Hg}(\mathrm{II})$ and $\mathrm{Pb}$ (II) metal ions. The adsorption of metal ion was found to be dependent on $\mathrm{pH}$ and contact time apart form other factors. The work highlights an enhanced rate of adsorption, which is attributed to the large BET surface area of $740 \mathrm{~m}^{2} / \mathrm{g}$. The after use analysis of fiber showed the possibility of its re-use. A detailed discussion on mass transfer mechanism, taking into picture both intra particle and film diffusion control is taken up. The nature of the plot indicated that the mass transfer process is rather complex. The equilibrium isotherm behavior was tested using Langmuir and Freundlich isotherms and the favorability factor was discussed. Taking into account the regression values and values of favorability factor, the $\mathrm{Hg}(\mathrm{II})$ and $\mathrm{Pb}$ (II) adsorption seem to follow Freundlich and Langmuir pattern, respectively. That is, $\mathrm{Hg}(\mathrm{II})$ and $\mathrm{Pb}(\mathrm{II})$ adsorption shows multilayer and monolayer uptake phenomena, respectively. TNF showed a great affinity for both $\mathrm{Hg}$ and $\mathrm{Pb}$ and can be a potential candidate for adsorption of other metals as well.

\section{ACKNOWLEDGMENT}

The authors would like to thank Department of Chemical Engineering (IIT-BHU) for providing help with sample characterizations.

\section{REFERENCES}

[1] R. L. Brathwaite and S. D. C. Rabone, "Heavy metal sulphide deposits and geochemical surveys for heavy metals in New Zealand," J. R. Soc. N. Z., vol. 15 , no. 4, pp. 363-370, 1985

[2] Metcalf and Eddy Inc.,WasteWater Engineering: Treatment Disposal and Reuse, 3 edition, revised by G. Tchobanoglous, F. Burton, McGraw-Hill Inc., Singapore, 1991.

[3] M. Firouzzare and Q. Wang, "Synthesis and characterization of a high selective mercury(II)-imprinted polymer using novel aminothiol monomer, " Talanta., vol. 101, pp. 261-266, 2012.

[4] K. Kadirvelu, M. Kavipriya, C. Karthika, N. Vennilamani, and S Pattabhi, "Mercury (II) adsorption by activated carbon made from sago waste," Carbon, vol. 42, pp. 745-752, 2004.

[5] X. Liu, Q. Hu, Z. Fang, X. Zhang, and B. Zhang, "Magnetic chitosan nanocomposites: A useful recyclable tool for heavy metal ion removal," Langmuir, vol. 25, pp. 3-8, 2009.

[6] R. Q. Long and R. T. Yang, "Carbon nanotubes as superior sorbent for dioxin removal," J. Am. Chem. Soc, vol. 123, pp. 2058-2059, 2001.

[7] G. N. Chaudhari, D. R. Bambole, and A. B. Bodade, "Characterization of nanosized $\mathrm{TiO}_{2}$ based $\mathrm{H}_{2} \mathrm{~S}$ gas sensor," J. Mater. Sci., vol. 41, pp. 4860-4864, 2006.

[8] C. L. Chen and H. S. Weng, "Nanosized $\mathrm{CeO}_{2}$-supported metal oxide catalysis for catalytic reduction of $\mathrm{SO}_{2}$ with $\mathrm{CO}$ as a reducing agent,"Appl. Catal. B-Environ., vol. 55, pp. 115-122, 2005.

[9] S. J. Park, S. Bhargava, and E. T. Bender, "Palladium nanoparticles supported by alumina nanofibers synthesized by electrospinning," $J$. Mater. Res., vol. 23, pp. 1193-1196, 2008.

[10] V. Tomer, R. Teye-Mensah, J. C. Tokash, N. Stojilovic, W. Kataphinan, E. A. Evans, G. G. Chase, R. D. Ramsier, D. J. Smith, and D. H. Reneker, "Selective emitters for thermophotovoltaics: erbiamodified electrospun titania nanofibers," Sol. Energy Mater. Sol. Cells. vol. 85, pp. 477-488, 2005.

[11] S. K. Pradhan, P. J. Reucroft, F. Yang, and A. Dozier, "Growth of $\mathrm{TiO}_{2}$ nanorods by metalorganic chemical vapor deposition," J. Cryst. Growth., vol. 256, pp. 83-88, 2003.

[12] J. Yang, S. Mei, and J. M. F. Ferreira, "Hydrothermal synthesis of nanosized titania powders: Influence of tetraalkyl ammonium hydroxides on particle characteristics," J. Am. Chem. Soc., vol. 84, pp. 1696-1702, 2001.

[13] H. Parham, B. Zargar, and R. Shiralipour, "Fast and efficient removal of mercury from water samples using magnetic iron oxide nanoparticles modified with 2-mercaptobenzothiazole," J. Hazard. mater., vol. 205-206, pp. 94-100, 2012.

[14] Z. Ghasemi, A. Seif, T. S. Ahmadi, B. Zargar, F. Rashidi, and G. M. Rouzbahani, "Thermodynamic and kinetic studies for the adsorption of $\mathrm{Hg}(\mathrm{II})$ by nano- $\mathrm{TiO}_{2}$ from aqueous solution," Adv Powder Technol., vol. 23 , pp. 148-156, 2012.

[15] O. Hakami, Y. Zhang, and C. J. Banks, "Thiol-functionalised mesoporous silica-coated magnetite nanoparticles for high efficiency removal and recovery of $\mathrm{Hg}$ from water," Water Res., vol. 46, no. 12 , pp. 3913-3922, 2012.

[16] A. Dixit, K. Atal, P. K. Mishra, and M. S. Alam, "Removal of Mercury(II) through adsorption on Titania Nanofibers," Asian $J$. Chem., vol. 27, no. 12, 2015.

[17] B. H. Hameed, A. T. M. Din, and A. L. Ahmad, "Adsorption of methylene blue onto bamboo-based activated carbon: kinetics and equilibrium studies," J. Hazard. mater., vol. 141, no. 3, pp. 819-825, 2007.

[18] A. G. El-Said, N. A. Badawy, and S. E. Garamon, "Adsorption of cadmium (II) and mercury (II) onto natural adsorbent rice husk ash (rha) from aqueous solutions: Study in single and binary system," International J. Chem., pp. 58-68, 2012.

[19] W. J. Weber Jr and J. C. Morris, "Kinetics of adsorption on carbon from solution," J. Sanit. Eng. Div. Am. Soc. Civ. Eng., vol. 89, pp 31-60, 1963.

[20] G. E. Boyd, A. W. Adamson, and L. S. Myers-Jr., "The exchange adsorption of ions from aqueous solutions by organic zeolites: Kinetics," J. Am. Chem. Soc., vol. 69, pp. 2836-2848, 1947.

[21] Y. S. Ho, "Isotherm for the sorption of lead onto pead: Comparison of linear and non-linear methods," Pol. J. Environ. Stud., vol. 15, pp. 81-86, 2006

[22] J. Cao, Y. Tan, Y. Che, and H. Xin, "Novel complex gel beads composed of hydrolyzed polyacrylamide and chitosan: An effective adsorbent for the removal of heavy metal from aqueous solution," Bioresour. Technol., vol. 101, pp. 2558-2561, 2010.

[23] M. Arshadi, "Manganese chloride nanoparticles: A practical adsorbent for the sequestration of $\mathrm{Hg}(\mathrm{II})$ ions from aqueous solution," Chem Eng J., vol. 259, pp. 170-182, 2015.

[24] K. Hardani, F. Buazar, K. Ghanemi, M. Kashisaz, M. H. Baghlani-Nezhad, A. Khaledi-Naseb, and M. Badri, "Removal of toxic mercury (II) from water via $\mathrm{Fe}_{3} \mathrm{O}_{4}$ /hydroxyapatite nanoadsorbent: An efficient, economic and rapid approach," Amer. Assoc. Sci. Tech. J. Nanosci., vol. 1, no. 1, pp. 11-18, 2015.

[25] J. Song, H. Kong, and J. Jang, "Adsorption of heavy metal ions from aqueous solution by polyrhodanine-encapsulated magnetic nanoparticles," J. Colloid Interface Sci., vol. 359, pp. 505-511, 2011.

[26] B. Dou, V. Dupont, W. Pan, and B. Chen, "Removal of aqueous toxic $\mathrm{Hg}$ (II) by synthesized $\mathrm{TiO}_{2}$ nanoparticles and $\mathrm{TiO}_{2} /$ montmorillonite,' Chem Eng J., vol. 166, pp. 631-638, 2011.

[27] X. Guo, B. Dua, Q. Wei, J. Yang, L. Hu, L. Yan, and W. Xua "Synthesis of amino functionalized magnetic graphenes composite material and its application to remove $\mathrm{Cr}(\mathrm{VI}), \mathrm{Pb}(\mathrm{II}), \mathrm{Hg}(\mathrm{II}), \mathrm{Cd}(\mathrm{II})$ and $\mathrm{Ni}(\mathrm{II})$ from contaminated water," J. Hazard. mater., vol. 278, pp 211-220, 2014.

[28] S. Pan, Y. Zhang, H. Shen, and M. Hua, "An intensive study on the magnetic effect of mercapto-functionalized nano-magnetic $\mathrm{Fe}_{3} \mathrm{O}_{4}$ polymers and their adsorption mechanism for the removal of $\mathrm{Hg}$ (II) from aqueous solution," Chem Eng J., vol. 210, pp. 564-574, 2012.

[29] A. Mahapatra, B. G. Mishra, and G. Hota, "Electrospun $\mathrm{Fe}_{2} \mathrm{O}_{3}-\mathrm{Al}_{2} \mathrm{O}_{3}$ nanocomposite fibers as efficient adsorbent for removal of heavy metal ions from aqueous solution," J Hazard Mater., vol. 258-259, pp. 116-123, 2013.

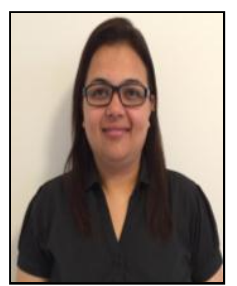

Abhilasha Dixit was born in India. She received her bachelor degree in chemical engineering in the year 2007 from University of Pune (Maharashtra) India. She got her master degree in chemical engineering (M.Tech) from National Institute of Technology, Surat (Gujarat), India from 2008-2010 and is currently doing her doctoral degree in chemical engineering from National Institute of Technology, Allahabad (UP), India.

She was entitled for scholarship for higher education during both her Masters and Doctoral degree. Her doctoral proposal was awarded TEQIP (Technical Education's Quality Improvement Program) grant from the institute. Her area of interest is environmental engineering, in particular, wastewater treatment. She did her bachelors project in wastewater treatment in a steel plant located in Hazira (Gujarat), India. Her masters thesis was on advanced oxidation processes (AOPs) for industrial wastewater treatment 
and her doctoral work is on nanotechnology for wastewater treatment. She has several publications.

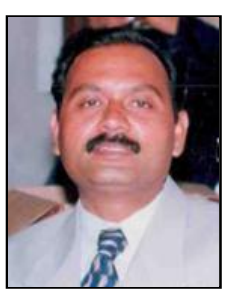

P. K. Mishra was born in India. He did his bachelors in chemical engineering from Indian Institute of Technology, Roorkee, India. He received his master degree in chemical engineering (M.Tech) from Indian Institute of Technology, Bombay, India, and $\mathrm{PhD}$ in chemical engineering from Indian Institute of Technology, IIT-BHU, Varanasi (UP), India.

$\mathrm{He}$ is currently serving as Head and Professor at the Department of Chemical Engineering, IIT-BHU, Varanasi (India). He has guided several PhDs and masters students and is involved with numerous government projects. His interests include separation processes and chemical reaction engineering. $\mathrm{He}$ has several publications.

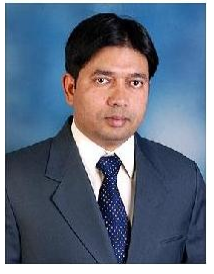

M. Siraj Alam was born in India. He did his master and $\mathrm{PhD}$ degrees in chemical engineering from Indian Institute of Technology, Roorkee, India. He is serving as Assistant Professor at the Department of Chemical Engineering, Motilal Nehru National Institute of Technology, Allahabad (UP), India.

His research interests include nucleate pool boiling, heat transfer, chemical reaction engineering, distillation, and separation processes. He has guided several PhDs and Masters students and has several publications. 